\title{
Michel Wasserman, Claudel Danse Japon
}

\section{Stefano Genetti}

\section{(2) OpenEdition}

\section{Journals}

\section{Edizione digitale}

URL: https://journals.openedition.org/studifrancesi/3200

DOI: $10.4000 /$ studifrancesi.3200

ISSN: 2421-5856

\section{Editore}

Rosenberg \& Sellier

\section{Edizione cartacea}

Data di pubblicazione: 1 juillet 2013

Paginazione: 484

ISSN: 0039-2944

\section{Notizia bibliografica digitale}

Stefano Genetti, «Michel Wasserman, Claudel Danse Japon», Studi Francesi [Online], 170 (LVII | II) | 2013 , online dal 30 novembre 2015, consultato il 31 janvier 2023. URL: http://journals.openedition.org/ studifrancesi/3200 ; DOI: https://doi.org/10.4000/studifrancesi.3200

\section{Questo documento è stato generato automaticamente il 31 janvier 2023.}

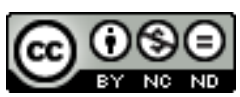

Creative Commons - Attribuzione - Non commerciale - Non opere derivate 4.0 Internazionale - CC BYNC-ND 4.0

https://creativecommons.org/licenses/by-nc-nd/4.0/ 


\title{
Michel Wasserman, Claudel Danse Japon
}

\author{
Stefano Genetti
}

\section{NOTIZIA}

Michel WASSERMAn, Claudel Danse Japon, Paris, Classiques Garnier, 2011 («Études de littérature des Xxe et XxI ${ }^{e}$ siècles», 23), pp. 160.

1 Ricalcando la triade valeriana Degas Danse Dessin, il titolo di questo saggio colloca i due "poemi coreografici" composti da Claudel nel solco del pensiero della danza di Valéry e, indirettamente, di Mallarmé: l'Après-midi del fauno Nijinsky aveva entusiasmato Claudel che - spettatore poco incline al balletto accademico, affascinato invece dall'euritmica di Dalcroze - concepiva la danza innanzi tutto come slancio vitale e spirituale. Attingendo abbondantemente al diario del poeta e a fonti d'archivio parzialmente riportate in appendice, il volume, corredato di illustrazioni, ci guida in un viaggio geo-culturale, psico-biografico e creativo: da Rio de Janeiro a Tokyo, passando per avenue Montaigne, tra incarichi diplomatici e momenti di vita interiore, contatti occasionali e sodalizi, apprensioni e delusioni. Lungo questo itinerario, l'A. entra nel dettaglio non solo della gestazione e della realizzazione, ma anche dell'accoglienza - controversa, se non ostile - riservata nel 1921 a L'Homme et son désir e, due anni dopo, a La Femme et son ombre.

2 Ideato per Nijinsky fin dal 1917, in occasione della tournée sudamericana dei Ballets Russes, il primo mette in scena l'animarsi, in sogno, dell'Uomo, immerso negli elementi della natura e nell'armonia universale rappresentata dalla marcia delle Ore, a confronto con un'immagine dicotomica della donna che associa amore e morte, passione e disillusione. Complici le reticenze di Diaghilev e il degradarsi della salute mentale del danzatore russo, il poème plastique venne interpretato da Jean Börlin, la cui seminudità fece scandalo. Fu infatti allestito al Théâtre des Champs-Élysées dai Ballets Suédois di Rolf de Maré, impresario audace e animatore, tra primitivismo e avanguardismo, di una breve ma cruciale stagione interartistica cui contribuirono 
anche Cocteau e Cendrars e culminata con Relâche (1924), nonché lungimirante fondatore delle Archives Internationales de la Danse, attualmente custodite presso il Dansmuseet di Stoccolma, dove l'A. si è ampiamente documentato. Se lo spazio lasciato alle percussioni nella partitura di Milhaud restituisce i suoni della foresta tropicale, la verticalità della scenografia disegnata da Audrey Parr richiama quella dell'Annonce faite à Marie e prelude, nella sua portata simbolica, all'Amphion di Valéry. Disponendo le figure su praticabili sovrapposti come una frase musicale sul pentagramma, tale dispositivo corrisponde tanto all'estetica del tableau in movimento tipica dei Suédois quanto alla claudeliana teoria degli «acteurs permanents» (p. 31), poiché dei personaggi viene privilegiata la portata allegorica, metafisica, alla funzione mimetico-narrativa.

A Tokyo, sollecitato dagli ambienti del Kabuki, il poeta di Connaissance de l'Est non si limita ad adattare il suo "poème cosmique» (p. 104) al gusto e alla tradizione teatrale giapponese, bensì riscrive l'argument. L'atmosfera notturna si fa più rarefatta e, segnando la transizione dal mimodramma al drame lyrique, le due redazioni successive di La Femme et son ombre rispecchiano un intreccio spettrale, costruito sullo sdoppiamento allucinatorio dell'immagine maschile e di quella femminile, a sua volta duplicato nel décor dai movimenti inversi della luna nel cielo e del suo riflesso sull'acqua. Il gemellaggio di danza e poesia, di stilizzazione del gesto e distillazione verbale, evidenzia una concezione luminiscente e trasognata del palcoscenico in quanto spazio ritmico.

Nel completare il percorso che da L'Homme et son désir, sul quale si erano già soffermate Monique Dubar (Claudel "trouveur de la danse", "Cahier de l'Herne», 1997, pp. 308-325) e Mary Fleischer (Embodied Texts, Rodopi, 2007, pp. 253-301), conduce a La Femme et son ombre, M. Wasserman moltiplica i riferimenti alla drammaturga claudeliana, interrogandone anche l'effettiva parentela con il teatro orientale e con il Nô in particolare. Sottolinea così la centralità della metamorfosi di un «ballet brésilien [...] en drame lyrique à la japonaise [...] dans l'évolution de la carrière dramatique de Claudel dont elle constitue comme le châinon qui relie l'un à l'autre les deux grands ensembles, poétique et lyrique, qui composent l'édifice» (p. 121). 